\title{
Ruptura con la heteronormatividad predominante: construcción de personajes jóvenes en las series de ficción televisiva
}

\author{
Rupture with the predominant heteronormativy: construction of young \\ characters in television fiction series
}

\author{
Dra. María del Mar Ramírez-Alvarado \\ Universidad de Sevilla | Calle Américo Vespucio, 27, 41092 Sevilla | España | \\ http://orcid.org/0000-0002-0810-7879 | delmar@us.es \\ Dra. Lucía Ballesteros-Aguayo \\ Universidad de Sevilla | Calle Américo Vespucio, 27, 41092 Sevilla | España | \\ http://orcid.org/0000-0003-1191-4070 | Iballesteros@us.es

\section{Dra. M. Cruz Tornay-Márquez} \\ Universidad de Nebrija | Calle Santa Cruz de Marcenado, 27, 28015 Madrid | España | \\ http://orcid.org/0000-0003-3075-691X | mtornay@nebrija.es
}

Fechas | Recepción: 16/11/2020 | Aceptación: 21/01/2021

\section{Resumen}

Este trabajo ofrece una reflexión general sobre la presencia de la diversidad sexual en personajes jóvenes de series televisivas que han alcanzado éxito en una plataforma de notable penetración como lo es Netflix. Para ello se ha procedido a un análisis de dos de sus series de ficción de mayor difusión y que han constituido el corpus de análisis. Ambas han sido producidas en contextos culturales muy diferentes: La casa de las flores (serie mexicana, tres temporadas, estrenada en agosto de 2018) y Sex Education (serie británica, dos temporadas, estrenada en enero de 2019). Las conclusiones de este trabajo advierten que, efectivamente y siendo la heteronormatividad el canon dominante, esta visibilidad de orientaciones sexuales y su manifestación en personajes juveniles supone un avance. De hecho, no pocos de los personajes jóvenes estudiados afrontan sus realidades personales y deseos con importantes conflictos pero con decisión. Sin

\section{Abstract}

This paper offers a general reflection on the presence of sexual diversity in young characters in television series that have achieved success on a platform of notable penetration such as Netflix. To do this, an analysis of two of its most widely disseminated fiction series has been carried out and, has constituted the corpus of analysis. Both series have been produced in very different cultural contexts: La casa de las flores (Mexican series, three seasons, released in August 2018) and Sex Education (British series, two seasons, released in January 2019). The conclusions of this work warn that, effectively and with heteronormativity being the dominant canon, this visibility of sexual orientations and their manifestation in juvenile characters represents an advance. In fact, not a few of the young characters studied face their personal realities and desires with important but decisive conflicts. However, the conclusions also question whether this presence has effectively led to a greater acceptance of sexual diversity 
embargo, las conclusiones también cuestionan el hecho de si esta presencia ha supuesto una mayor aceptación de la diversidad sexual o, al contrario, si se presentan a estos personajes en el marco de convenciones culturales establecidas reforzando el heterosexismo, valores tradicionales como la familia o la monogamia, o haciendo énfasis en la asociación entre homosexualidad y falta de masculinidad o feminidad.

Palabras clave: televisión, Netflix, ficción televisiva, juventud, género. or, on the contrary, if these characters are presented within the framework of established cultural conventions reinforcing heterosexism, traditional values such as family or monogamy, or emphasizing the association between homosexuality and lack of masculinity or femininity.

Keywords: television, Netflix, television fiction, youth, gender.

\section{INTRODUCCIÓN}

En los últimos años, los productos audiovisuales que se emiten a través de las grandes plataformas de televisión digital han sido sensibles a la visibilización de distintas orientaciones sexuales y de estilos de vida diversos que han comenzado a ser incluidos en las más diversas tramas. El estudio que hemos llevado a cabo ofrece una reflexión general sobre la presencia de la diversidad de opciones sexuales de personajes jóvenes como estrategia y de forma recurrente en series que están alcanzando gran éxito en una plataforma de notable penetración actualmente como lo es Netflix.

Para ello se ha procedido a un análisis de dos de sus series de ficción de mayor difusión y que han constituido el corpus de análisis de este trabajo. Ambas series ofrecen personajes en esta línea y han sido producidas en contextos culturales muy diferentes. Por una parte, La casa de las flores, serie mexicana que constituye una revisión de las tradicionales telenovelas latinoamericanas, que ya va por su tercera temporada, y que se estrenó en agosto de 2018. Y, por otra, la serie británica Sex Education, también con dos temporadas y preparando la tercera, que se estrenó un poco más tarde, en enero de 2019. Ambas comparten el hecho de que son series de humor, con tintes que rozan en ocasiones el drama, y que se mueven notablemente en el entorno familiar.

Como premisa principal de este trabajo partimos de la idea de que, ciertamente, en los últimos años se ha producido un repunte en la incorporación de personajes de distintas orientaciones sexuales en las series televisivas (Guarinos, 2013). Además, no solo se trata de un incremento que puede constatarse, sino también que no pocos de estos personajes han comenzado a ser protagónicos, como se apunta en este estudio.

Sin embargo, las cuestiones abordadas en las distintas tramas invitan a ir más allá de la representación numérica que efectivamente se ha producido para preguntarnos entonces si esta mera representación de personajes de orientaciones sexuales diversas en las series televisivas emitidas a través de las grandes plataformas ha influido en actitudes positivas hacia las personas LGTB cambiando las nociones heteronormativas de la masculinidad y los modelos hegemónicos/tradicionales de las relaciones sociales. 


\section{REVISIÓN TEÓRICA: ACOTANDO CONCEPTOS CLAVES}

La sociedad como sistema posee unas funciones primordiales organizativas y de abastecimiento de los bienes y servicios materiales y con este fin se provee de determinados instrumentos y mecanismos de control que prestan estabilidad a la estructura social a la vez que permiten los cambios sociales. Esa es la función que ejercen, entre otros factores, las leyes, las normas y la cultura.

Los agentes de socialización (principalmente la familia, la educación y los medios de comunicación) propician la inserción de un individuo en un grupo social al tiempo que le asignan determinadas funciones y roles. Los papeles sociales y estatus socialmente compartidos establecen los marcos de referencia en los que se encuadra cada posición individual en el conjunto del entorno social y además la define en diferencia con la de los demás. Lógicamente cada sociedad es competente para establecer sus roles y sus normas de forma autónoma, por lo que estos son solo el resultado de determinadas convenciones sociales. Sin embargo, hay formas de conducta cuya normatividad le viene impuesta al individuo de una forma heterónoma.

\subsection{Heteronomía vs Autonomía}

Históricamente una de las defensas más genuinas en favor de la ruptura de la heteronomía en el plano moral la encontramos en el pensamiento kantiano. Autonomía versus Heteronomía son los sistemas categoriales desde los que plantea la ética kantiana el marcado carácter moral de los actos. La traducción, estudio y notas de la Fundamentación de la metafísica de las costumbres de Kant que lleva a cabo Smilg Vidal (Kant, 1996, p.102) señala marcadas diferencias entre los dos conceptos contrapuestos. En este sentido, define autonomía como "propiedad de la voluntad por la que sólo está sometida a aquellas leyes derivadas de sí misma en cuanto legisladora universal". Y heteronomía como

Situación en la que la voluntad obedece normas externas a ella y que no considera como propias, sino que le vienen impuestas. Esto sucede unas veces por miedo a las consecuencias negativas que se pudieran derivar de su no cumplimiento y otras porque la voluntad busca expresamente algún fin meramente empírico.

Esto es, moral autónoma es aquella en la que la voluntad es la que dictamina sus propias leyes de acción moral teniendo en cuenta las máximas que emanan de su propia razón y las características derivadas de la condición de su ser. En cambio, cuando la voluntad no es la que dicta sus propias leyes, sino que éstas le vienen impuestas externamente al individuo y las acepta por miedo, por buscar el reconocimiento social, por sentirse integrado, o por otros motivos resultantes de convenciones o pactos sociales, entonces hablamos de heteronomía.

Acatar la normatividad de estándares de naturaleza social ajenos a la naturaleza biológica permite a la persona una integración coherente con las normas y preceptos socialmente establecidos, pero lleva implícitos serios problemas de libertad habida cuenta de la disfunción y desemejanza con su consideración biológica que le conduce inexorablemente a transitar hacia determinadas fuentes de conducta inauténtica. En cambio, un comportamiento autónomo, aunque disidente de las convenciones normativas sociales comúnmente aceptadas, se convierte en el sustento de la libertad como fuente de la autenticidad. 
Tabla 1

Cuadro comparativo. Características de heteronomía y autonomía

\begin{tabular}{|c|c|}
\hline Heteronomía & Autonomía \\
\hline Fuente de todos los principios inauténticos & Fuente de autenticidad \\
\hline La voluntad no se da a sí misma las leyes & La voluntad dictamina sus propias leyes \\
\hline Comportamientos impuestos externamente & Comportamientos desde la propia persona \\
\hline Enmascara el problema de la libertad & Posibilita la libertad \\
\hline Emana de la experiencia como una convención & Emana de la razón \\
\hline
\end{tabular}

Fuente: elaboración propia.

\subsection{Convencionalismos sociales}

En relación a nuestro objetivo, conviene señalar que es posible una ruptura de la hegemonía de la heterosexualidad normativa predominante por su asentamiento sobre pilares puramente convencionales en la asignación de roles afectivo-emocionales que subyacen a la cosmovisión de la ciudadanía habida cuenta de que la identidad personal se forma a partir de las percepciones identificativas de reconocimiento social (roles, estatus, relaciones, estereotipos y todos los elementos del entorno cultural, entre los que se encuentran también las leyes) a las que se les unen los elementos heredados (el sexo, la edad, la familia, las aptitudes, y todo aquello genéticamente determinado).

La convencionalidad en la implantación de unas formas sexo-afectivas en detrimento de otras puede entrar en colisión con el carácter de la naturaleza del yo. La diferencia entre aquello que

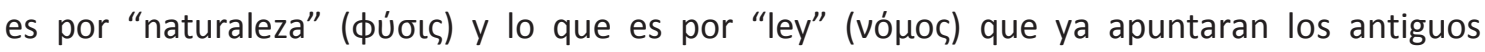
filósofos presocráticos nos permite establecer el origen pactado -y en consecuencia relativo, convencional- de las leyes que rigen en una sociedad, a diferencia de aquellas que vienen establecidas por mandato divino, o implícitas en la naturaleza humana. Esta dicotomía physis/nómos es la que sustenta que la asignación de roles sexuales asignados a hombres y mujeres no siempre tiene su raíz en la physis, sino que viene determinada por convenciones sociales más o menos institucionalizadas que marcan estereotipos de conducta, así como el carácter normativo en el plano afectivo, al margen a veces de su naturaleza biológica.

Numerosos trabajos de campo y líneas matrices de investigación avalan la correspondencia entre las condiciones culturales, la educación y los roles sociales asignados a las mujeres y a los hombres. En concreto, apunta Mead (1994, p. 14):

He estudiado este asunto entre los plácidos montañeses arapesh, los fieros caníbales mundugumor y los elegantes cazadores de cabezas de Tchambuli. Cada una de estas tribus tenía, como toda la sociedad humana, el problema de las diferencias de los sexos, tema importante en el plan de la vida social, que cada una de estas tres tribus desarrolló de diferente manera. Comparando la forma en que han destacado las diferencias entre los sexos, es posible profundizar nuestros conocimientos acerca de qué elementos son elaboraciones sociales, originalmente ajenos a los hechos biológicos del género de los sexos. 
Ciertamente, una convención es un pacto que no siempre tiene un carácter normativo, pero sí una marcada obligatoriedad tácita habida cuenta de que su violación conlleva algún tipo de castigo o de conflicto. Ello nos permite identificar que el origen del triunfo de la heteronormatividad como canon dominante en nuestra sociedad, su acatamiento, prolongación temporal y el rechazo de la diversidad sexual que lleva emparejado se fundamentan en el constructo cognoscitivo de los roles transmitidos en los procesos de socialización que transmiten modelos estandarizados -e incluso a veces institucionalizados- de empoderamiento en ocasiones al margen del yo que los sustenta, por lo que puede desencadenar determinados conflictos identitarios o afectivos.

\subsection{El género como constructo social}

El carácter sociocultural del género implica la implantación de una normatividad acorde con las relaciones afectivas que se impone como paradigma modélico para cada sociedad concreta. En el caso de nuestra cultura el predominio del patriarcado como modelo predominante promueve que se estandarice ese modelo-tipo heterosexual a través de las cogniciones en los procesos de enculturación, lo que permite crear en la mente humana una percepción socialmente compartida de predominio del varón y de la masculinidad hegemónica que conlleva una normatividad sexo-afectiva al margen incluso de las aspiraciones, deseos, voluntades que emanan del propio yo con el que, en ocasiones, puede entrar incluso en conflicto.

El género es, pues un constructo social aprendido que impone ciertas normas al sujeto de forma heterónoma; su opuesto, la autonomía, se constituye en el desiderátum por el que toda autoimposición normativa debería ser el objetivo de cualquier acción individual identitaria como constructo de su ideal personal en relación con los medios-fines a los que aspira y a partir de los que encuentra su culminación, su dignidad y su felicidad, al margen de cualquier imposición social.

\subsection{Sexo y género}

Sexo y género representan vectores imprescindibles en la formación de la identidad personal que conviene deslindar a fin de determinar su alcance. Para ello suscribimos la diferencia que desarrolla la Guía de transición ecosocial y principios éticos para nuestros medios (Chaparro Escudero et al., 2020, p. 125) que señala que: "el género se constituye por una serie de características de origen sociocultural; el sexo tiene un origen biológico. Género y sexo no son equivalentes. Y ninguno de los dos define la orientación sexo-afectiva de una persona".

Sostienen estos autores (2020, p. 126) que la construcción social del género viene condicionada por la tríada sexo-identidad de género-orientación sexual:

El sexo está determinado por características biológicas y distingue entre hombres y mujeres. En ningún caso, el sexo define el género. La identidad de género se corresponde con lo que la persona siente que es: hombre, mujer, u otro. La identidad de género no tiene por qué coincidir con el sexo biológico de la persona ni con su orientación sexo-afectiva. La orientación sexual o afectiva se define a partir de por quién o quiénes una persona siente atracción. Se suele hablar de tres orientaciones sexuales diferentes, heterosexualidad, homosexualidad y bisexualidad, aunque hay otras. Existen, asimismo, personas que no sienten atracción sexual por ninguna otra persona. 
La tendencia a la ruptura de la heteronormatividad de las masculinidades hegemónicas determina el abandono paulatino de la supremacía normativa y exclusiva del patriarcado en el orden sexoafectivo de manera que la autonomía, la diversidad y la apertura a diversas formas de orientación sexual son posibles más allá de los cánones sociales predominantes estereotipados y predeterminados. Estas novedosas orientaciones afectivas son las que parece que comienzan a emerger en las series más visionadas por nuestros jóvenes en la actualidad y hacia ellas va dirigido nuestro estudio.

\subsection{La representación del género}

Los estudios sobre el análisis de la representación con perspectiva de género han demostrado de manera recurrente la prevalencia de roles de género tradicionales tanto en cine y series, como en medios de comunicación (Tuchman, 1978; Mattelart, 1981; Global Monitoreo Media Project, 2015). Sin embargo, como demuestra Berger (1972), la representación desde una perspectiva de género ha respondido a cánones muy similares a lo largo de la historia del arte que se observan, a su vez, en las imágenes más contemporáneas. De manera general, los roles patriarcales se han trasladado a las producciones audiovisuales con la representación de hombres y mujeres de acuerdo a las identidades tradicionales de género. En este sentido, las mujeres han aparecido, de forma mayoritaria, en el papel de ama de casa, madre y esposa (Camps, 2013) o, de forma antagónica, en el rol de femme fatale (Doane, 1991) que evoca a la dualidad de la identidad femenina en la cultura occidental.

La representación de los roles tradicionales de género ha implicado, a su vez, el predominio de la heterosexualidad normativa y la invisibilización de otras orientaciones sexuales. La vigencia del Código Hays entre 1934 y 1967 impidió las alusiones a la homosexualidad en el cine de Hollywood, si bien, algunos cineastas se valieron de recursos simbólicos para sorterar el sistema de censura moral impuesto durante estas décadas (Durán, 2020). La sustitución del Código Hyes por un sistema de consejos generales permitió la adaptación de las producciones a los nuevos tiempos y, por tanto, mayor permisividad respecto a escenas de desnudos, relaciones interraciales o cuestiones sociales (Rodríguez de Austria, 2015). Sin embargo, el fin de la censura no supuso cambios notables en la representación de la homosexualidad y de las relaciones entre personas del mismo sexo. En la década de los setenta se estrenan las primeras películas con referencias directas a relaciones y personajes homosexuales, aunque impregnadas de connotaciones negativas y estereotipadas que provocaron el rechazo del emergente movimiento LGTBI. En la década de los noventa, y coincidiendo con la eliminación de la homosexualidad de la lista de enfermedades mentales de la Organización Mundial de la Salud (OMS), aparecen producciones destinadas al gran público -más allá de los canales de distribución alternativos- que permiten sensibilizar sobre la discriminación y rechazo social al colectivo gay.

En el contexto de la representación de la homosexualidad, es pertinente destacar cómo las mujeres vuelven a perder presencia. Las relaciones lésbicas no siempre se han mostrado de manera explícita y en ellas ha predominado la narrativa de la amistad entre mujeres adultas, como ocurriera en los clásicos feministas Thelma \& Louise (Ridley Scott, 1991) o Tomates verdes fritos (Jon Avnet, 1991).

La industria audiovisual nunca fue ajena a los cambios y tendencias sociales y, de manera más contemporánea, cine y series de televisión han incluido personajes que representan la 
homosexualidad de manera natural (Ramírez y Cobo, 2013). Aun con la presencia de estereotipos y clichés (Peters, 2011), la serie Queer as Folk, emitida originalmente en Reino Unido (1999), llegó a ser un referente mundial al convertirse en la primera serie protagonizada exclusivamente por personajes gays y, desde entonces, la representación de la diversidad en las producciones audiovisuales pasa necesariamente por la inclusión de identidades LGTBI.

De manera más reciente, algunas formas de representación de la diversidad han sido identificadas como estrategias de captación de las audiencias LGTBI. En este sentido, el queerbaiting -anzuelo queer- es el término utilizado para definir aquellas narrativas que reflejan tensión sexual o romanticismo entre personas del mismo sexo sin que finalmente se desarrolle una relación homosexual.

\section{SERIES ESTUDIADAS, PERSONAJES Y TRAMAS ASOCIADAS}

Desde el punto de vista metodológico, para esta investigación se ha trabajado con una plantilla de análisis que se centra en tres parámetros. Por una parte, se ha trabajado en la descripción y enfoques generales de la serie. En segundo término, se ha abordado la identificación y características de los personajes a nivel del relato desde la perspectiva de la narrativa de carácter estructuralista (Casetti y Di Chio, 2007). Y, finalmente, en tercer lugar se ha procedido al estudio de las tramas asociadas.

\subsection{La casa de las flores}

Tabla 2

Datos de la serie

\begin{tabular}{|l|l|}
\hline \multicolumn{1}{|c|}{ Serie } & \multicolumn{1}{|c|}{ La casa de las flores } \\
\hline Plataforma: & Netflix \\
\hline País: & México \\
\hline Dirección: & Creada por Manolo Caro \\
\hline Temporada 1 & 13 episodios, estrenada el 10 de agosto de 2018 \\
\hline Temporada 2: & 9 episodios, estrenada el 18 de octubre de 2019 \\
\hline Temporada 3: & 11 episodios, estrenada el 23 de abril de 2020 \\
\hline Localizaciones: & Ciudad de México, Madrid \\
\hline Duración de los capítulos: & Entre 27 y 37 minutos \\
\hline Actrices/ actores principales & $\begin{array}{l}\text { Verónica Castro (Virginia Aguirre de la Mora), Cecilia Suárez } \\
\text { (Paulina de la Mora), Claudette Maillé (Roberta Sánchez), Dario } \\
\text { Yazbek Bernal (Julián de la Mora), Aislinn Derbez (Elena de la } \\
\text { Mora), Juan Pablo Medina (Diego Olvera), Paco León (José María } \\
\text { / María José Riquelme), entre otros }\end{array}$ \\
\hline
\end{tabular}

Fuente: elaboración propia.

La casa de las flores es una serie que pivota en torno a una floristería como espacio central en el que giran los personajes de la familia adinerada dueña, los de La Mora. A lo largo de la serie se abordan temáticas diversas vinculadas a los distintos miembros de este grupo familiar que van desde los altibajos en las relaciones matrimoniales, la infidelidad o la adicción a las drogas, pasando por el suicidio, las relaciones paterno-maternas/filiales, la amistad o la presentación 
del mundo del espectáculo. Su propio creador /director, Manolo Caro, señala haber apostado por la inclusión de la comunidad LGBT y, así, hay una presencia destacada de personajes gay, bisexuales y transexuales. También se incursiona en el universo drag y del cabaret nocturno.

Destacaremos de esta serie fundamentalmente tres personajes. Por una parte la pareja compuesta por el actor Julián de la Mora (Darío Yasbek), hijo de la protagonista central de la serie (Virginia de la Mora, representada por Verónica Castro, afamada primera figura de telenovelas mexicanas) que mantiene una relación con Diego (Juan Pablo Medina). Esta relación permite poner de relieve varias temáticas. Julián tiene una novia a la que considera hermosa, pero a la que no ama, ya que sus afectos profundos se dirigen a Diego, un hombre de negocios apuesto y con éxito. Con él mantiene una íntima relación secreta. Esta situación hace que la familia ( $y$ en especial su madre) viva, en diferentes fases, la situación de aceptación de un hijo homosexual.

Por otra parte, es relevante mencionar la incorporación de un personaje transgénero como lo es María José (Paco León), que inicia su andadura en La casa de las flores como José María, exesposo de Paulina de la Mora (Cecilia Suárez, otra de las protagonistas de la serie), y que avanza en la misma convirtiéndose en María José. Los ires y venires de esta pareja en las tres temporadas ofrecen un panorama complejo y a la vez interesante de la diversidad de opciones y de sus sentimientos asociados.

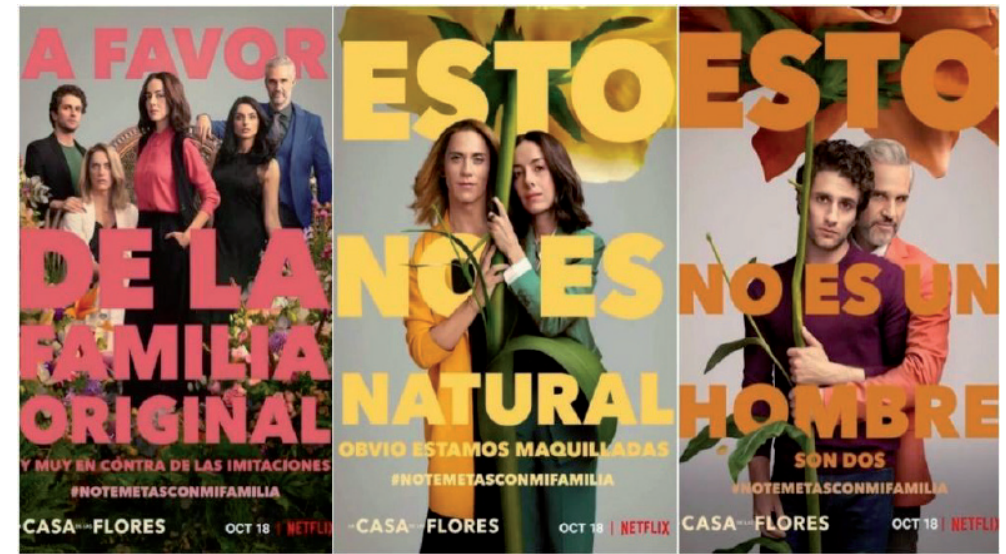

Figura 1. Carteles de La casa de las flores Fuente: Netflix

\subsection{Sex Education}

Tabla 2

Datos de la serie

\begin{tabular}{|l|l|}
\hline \multicolumn{1}{|c|}{ Serie } & \multicolumn{1}{c|}{ Sex Education } \\
\hline Plataforma: & Netflix \\
\hline País: & Reino Unido \\
\hline Dirección: & $\begin{array}{l}\text { Ben Taylor, Kate Herron, Sophie Goodhart y } \\
\text { Alice Seabright. Creada por Laurie Nunn }\end{array}$ \\
\hline Temporada 1: & 8 episodios, estrenada el 11 de enero de 2019 \\
\hline Temporada 2: & 8 episodios, estrenada el 17 de enero de 2020 \\
\hline
\end{tabular}




\begin{tabular}{|l|l|}
\hline Temporada 3: & En preparación (a estrenar en enero de 2021) \\
\hline Localizaciones: & Inglaterra y Gales \\
\hline Duración de los capítulos: & Entre 47-59 minutos \\
\hline Actrices/ actores principales & $\begin{array}{l}\text { Asa Butterfield (Otis Milburn), Gillian } \\
\text { Anderson (Jean F. Milburn), Ncuti Gatwa (Eric } \\
\text { Effiong), Emma Mackey (Maeve Wiley), Connor } \\
\text { Swindells (Adam Groff), entre otros }\end{array}$ \\
\hline
\end{tabular}

Fuente: elaboración propia.

La serie Sex Education se centra en la vida de un adolescente llamado Otis (Asa Butterfield) y en la relación que mantiene con su madre (Gillian Anderson), que es una terapeuta sexual. El espacio principal en el que confluyen los personajes es el Instituto Moordale, donde se sitúan los compañeros y profesores de Otis. Son fundamentalmente dos, Maeve (Emma Mackey, la chica dura, brillante y, en cierta medida, desadaptada de la que se enamora) y Eric (Ncuti Gatwa), su mejor amigo que es homosexual, negro y con familia de origen africano. A través de la relación con su madre, Otis ha desarrollado una gran empatía y conocimiento de distintas problemáticas de carácter sexual y su vínculo con las relaciones sentimentales, de allí que el gran negocio que se le ocurre a Maeve es el de que se convierta en terapeuta y asesor de sus amigos a cambio de una tarifa por sus servicios.

De esta serie destacan a efecto de este trabajo dos parejas. La primera de ellas es la compuesta por Eric y Adam (Connor Swindells), que ofrece tramas cruzadas de notable interés. Eric desde un inicio expresa su identidad sexual sin tapujos, tanto en su forma de ser como de actuar. En su camino está presente Adam, quien le persigue, amenaza, humilla e insulta en el más claro bullying. Pero esto es sólo al inicio porque, con el paso de los capítulos, termina enamorándose de él. En un punto determinado se incorpora Rahim (Sami Outalbali), un chico gay que llega al instituto desde Francia y se forma una especie de triángulo amoroso.

Por otra parte, hay dos tramas secundarias conexas con chicas lesbianas: una pareja de lesbianas interracial, por una parte, en la que se centra uno de los capítulos por la dificultad de ambas para mantener relaciones sexuales. La otra es la configurada por Ola Nyman (Patricia Allison), quien evoluciona de la heterosexualidad (se hace novia de Otis) al interés y deseo por Lily (Tanya Reynolds), una compañera de clase ilustradora de novelas eróticas llenas de monstruos extraterrestres, y que camina también en igual sentido.
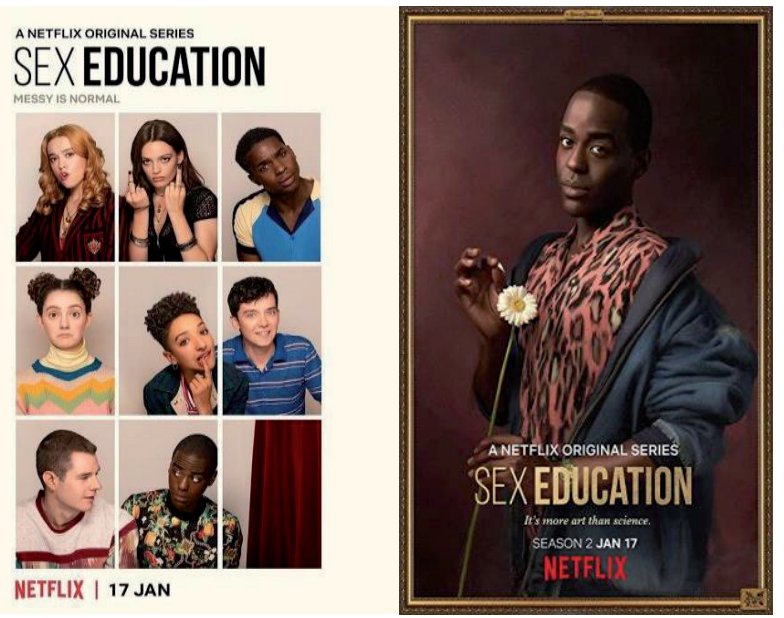

Figura 2. Carteles de Sex Education 
Fuente: Netflix

\section{ANÁLISIS Y CONCLUSIONES}

En líneas generales, podemos señalar como conclusiones que, efectivamente, las series de ficción llevan años ya abriéndose y siendo sensibles a la incorporación de personajes jóvenes con distintas orientaciones sexuales. Este hecho ha permitido el desarrollo de tramas que se alejan de las nociones heteronormativas de la masculinidad o feminidad, lo cual supone, ciertamente, un avance importante. La representación de personajes no heterosexuales protagonistas permite la visibilización y, por tanto, normalización, de las rupturas de las identidades tradicionales de género.

Sin embargo, a través del análisis de los personajes trabajados y de las tramas asociadas en La casa de las flores y en Sex Education dentro del contexto de este estudio han sido detectadas algunas cuestiones relevantes como las siguientes:

Asociación entre la homosexualidad y falta de masculinidad y del lesbianismo con la falta de feminidad. También el vínculo entre la homosexualidad y lo hiperbólico, exagerado, histriónico, desmedido y vinculado a situaciones jocosas, al igual que la idea del exceso de preocupación e interés por el aspecto físico. En este sentido, se presenta a estos personajes con estilo y personalidad, pero también superficiales, frívolos y extrovertidos. Ejemplo claro en las series trabajadas es el de dos personajes de Sex Education, el de Eric (personaje principal) y Anwar, siempre preocupado por el estilismo y por la moda.

Por oposición, puede hablarse de algunos elementos de hipermasculinidad gay que se identifican claramente en algunos de los personajes trabajados. Incluso, en algunos personajes se intenta buscar una imagen equiparable a la heterosexual, acentuando rasgos masculinos o femeninos dependiendo del caso. En la serie La casa de las flores puede mencionarse el ejemplo en esta línea de Diego, reforzado en la serie como un establecido hombre de negocios, que mantiene a escondidas una relación homosexual con Julián de la Mora. En Sex Education está el personaje de Adam, presentado en un inicio como hipermasculino en sus actitudes y conductas sexuales (incluso hay tramas vinculadas a las dimensiones de su pene), que termina descubriendo los sentimientos que alberga hacia Eric, a quien incluso ha sometido a escarnio y bulling. Y se incluye en el reparto a un estudiante francés que llega al Instituto y del que varias chicas se enamoran, pero que termina interesándose en Eric.

En no pocas ocasiones las tramas que involucran a estos personajes se nutren también de fórmulas narrativas tradicionales. Y así las relaciones están marcadas por celos, infidelidades y triángulos amorosos que aportan juego narrativo. Incluso está presente, por ejemplo en Sex Education, la idea del acosador del que se enamora el acosado y que, finalmente, descubre su homosexualidad. De igual manera, hay una notable presencia de recursos narrativos que refuerzan la tensión sexual.

Como aspecto relevante, se evidencia cómo la diversidad es un elemento central en el ejemplo de Sex Education, no solo en lo relativo a la orientación sexual, si no también en la participación de personajes racializados (Eric, Anwar o la pareja conformada por Ola y Lily), lo que, supone, a su vez, una ruptura de los cánones normativos de la televisión respecto a la hegemonía de la blanquitud. La representación de diversidades, en un sentido amplio, en una serie dirigida al público joven conecta con la influencia de corrientes de pensamiento queer, en 
las que la identidad del individuo toma protagonismo. Esto se aprecia de manera importante en distintos personajes de La casa de las Flores que conforman ese universo "cabaret" que da trasfondo a distintas tramas.

En relación a la diversidad de la orientación sexual, se considera relevante la visibilización de las transgresiones normativas como forma de naturalizar las disidencias de los patrones de género; sin embargo, este hecho contrasta con la identificación de narrativas vinculadas al mito del amor romántico que, en absoluto, involucran una ruptura de la heteronormatividad. La prevalencia de estas situaciones podría hacer cuestionar el interés en la superación de patrones heteronormativos que parecen seguir instalados en la juventud, entre ellos, situaciones de dominación, celos o violencia.

Finalmente, a través del estudio puesto en marcha puede dejarse por sentado el interés del análisis de productos audiovisuales como las series de televisión, de tanta importancia en el consumo actual por parte de los jóvenes y también de los adultos. En tanto agentes socializadores, los medios de comunicación tienen una enorme influencia en la construcción de identidades y relaciones de género. Se considera, por tanto, que la representación de las diversidades en las dos series analizadas supone un avance en dos sentidos: en el caso de la serie La casa de las flores, la visibilización de nuevas identidades de género y la ruptura de las formas tradiciones de masculinidad colaboran a la normalización de las rupturas heteronormativas. A este respecto, es importante destacar el respaldo de la audencia tanto en México como en otros países de la región latinoamericana cuyas producciones televisivas se han caracterizado, precisamente, por las representaciones heteronormativas. Por otro lado, la diversidad en Sex Education permite la naturalización de las rupturas heteronormativas en audiencias más jóvenes, pero también, problematizar acerca de la prevalencia de narrativas tradicionales asociadas a la dominación.

Los resultados de este trabajo también sugieren poner de relieve el valor académico de profundizar en tramas y personajes a fin de detectar los estereotipos que son presentados de forma indirecta, incluso sutil, a través de un medio de comunicación como lo es televisivo, tan instalado en la vida cotidiana de las personas y de proyección social.

\section{Referencias}

Berger, J. (1972). Modos de ver. Editorial Gustavo Gili.

Camps, V. (2013). El siglo de las mujeres. Traficantes de Sueños.

Casetti, F. y Di Chio, F. (2007). Cómo analizar un film. Paidós.

Chaparro Escudero, M., Espinar Medina, L., El Mohammadiane Tarbift, A. y Peralta García. L. (2020). Guía de transición ecosocial y principios éticos para nuestros medios. Fragua.

Doane, M.A. (1991). Femmes Fatales: Feminism, Film Theory, Psychoanalysis. Routledge.

Durán, V. (2020). Rompiendo el Código. Personajes y sexualidades latentes en el Hollywood clásico. Readuck.

Global Media Monitoring Project (2015). Who Makes the News? WACC.

Guarinos, V. (ed.) (2013). Hombres en serie: construcción de la masculinidad en los personajes de ficción seriada española de televisión. Fragua.

Kant, I. (1996). Fundamentación de la metafísica de las costumbres. Trad. estudio y notas por Smilg Vidal, N. Santillana. 
Mattelart, M. (1981). La mujer y las industrias culturales. UNESCO.

Mead, M. (1994). Sexo y temperamento. Altaya.

Peters, W. (2011). Pink Dollars, White Collars: Queer as Folk, Valuable Viewers, and the Price of Gay TV. Critical Studies in Media Communication, 28, 193-212.

Ramírez Alvarado, M. y Cobo Durán, S. (2013). La ficción gay-friendly en las series de televisión españolas. Comunicación y Sociedad, 19, 213-235.

Rodríguez de Austria, A.M. (2015). El código de producción de Hollywood (1930-1966): censura, marcos (frames) y hegemonía. ZER - Revista de Estudios de Comunicación, 20 (39), 177-193.

Tuchman, G. (1978). The Symbolic Annihilation of Women by the Mass Media. En Tuchman, G.; Kaplan, A. \& Benet, J. (eds.), Hearth and Home: Images of Women in the Mass Media. Oxford University Press.

\section{Semblanza de las autoras}

María del Mar Ramírez Alvarado es Profesora Titular del Área de Comunicación Audiovisual y Publicidad en la Facultad de Comunicación de la Universidad de Sevilla, de la que actualmente es decana. Es Licenciada y Doctora en Ciencias de la Información y su tesis doctoral obtuvo el Premio Extraordinario de Doctorado. Es autora de diversas publicaciones centradas en el ámbito de la historia de la comunicación y el estudio de imágenes insertas en distintos momentos de la historia; de la fotografía desde diversas perspectivas y de la televisión como medio de comunicación. Siempre he mantenido como línea transversal la perspectiva de género.

Lucía Ballesteros Aguayo es Doctora en Periodismo con una tesis doctoral sobre la prensa durante el franquismo en España. Actualmente es profesora de la Universidad de Sevilla y colabora en tareas de investigación con diferentes entidades internacionales como el Instituto Nacional de Documentación, Innovación e Investigación en Educación, INDIRE, de Florencia (Italia) o el DigiMedia Research Centre de la Universidad de Aveiro (Portugal). Ha realizado varias estancias de investigación en el extranjero y tiene una amplia producción científica sobre historia del periodismo, propaganda política, posverdad, efectos de la comunicación, donde podemos destacar "Humour in the post-war press: Short stories of Gloria Fuertes in the falangist magazine Maravillas" en Revista Latina de Comunicación Social o "Traitors of the Homeland: The stigmatization of reds in falangist discourse" en Peter Lang.

M. Cruz Tornay-Márquez es Doctora en Comunicación y máster en Estudios de Género y Desarrollo Profesional de la Universidad de Sevilla, y licenciada en Ciencias de Comunicación, especialidad Periodismo, por el Centro Andaluz de Estudios Empresariales (CEADE) (España). Actualmente es docente en la Universidad de Nebrija y es miembro del Grupo de Estudios e Investigaciones Educativas en Tecnologías de la Comunicación, Orientación e Intervención Sociocultural, Ágora, de la Universidad de Huelva, y de la Red de Investigación en Comunicación Comunitaria, Alternativa y Participativa (RICCAP). Sus líneas de investigación se enfocan en la alfabetización mediática, la comunicación para el desarrollo y el cambio social con énfasis en la perspectiva de género. 